\title{
OBITUARIES
}

\section{Prof. C.-G. Rossby}

Prof. CArl-Gustav Rossby, director of the Institute of Meteorology, University of Stockholm, died suddenly on August 19, at the age of fifty-nine. With his untimely death, meteorology has lost its most colourful, stimulating and provocative exponent of the past twenty years or so. Rossby was a native of Stockholm and graduated from its University in 1918. Geophyrsical science was 'quite the rage' in Scandinavia in those days and Rossby was immediately attracted to its 'Mecca', the Geophysical Institute at Bergen, where for the next two years he worked under Prof. V. Bjerknes, and with the several exponents of the famous air-mass and frontal school of meteorology. He continued his geophysical studies for a year at Leipzig, where V. Bjerknes had formerly occupied a chair, and then entered in 1932 the Swedish Meteorological and Hydrographic Service. In 1926, he was awarded a fellowship, by the SwedishAmerican Foundation, to propagate the gospel of the Bergen school among meteorologists in the United States, and this led, a year later, to his appointment under the Guggenheim Fund for Promotion of Aeronautics to apply meteorological knowledge more effectively to aviation. The role was exacting and, apparently, often exciting; but it failed to satisfy the scholar that lay somewhat hidden behind the many other qualities that made up Rossby.

In 1928, the Massachusetts Institute of Technology invited Rossiby to become its first head of a department of meteorology. When he left it, in 1939, academic meteorology was well founded in the United States. For the next two years Rossby was assistant chief of research to the U.S. Weather Bureau, but on America's entry into the War he was appointed to a new chair of meteorology at the University of Chicago and directed a large effort on the rapid training of meteorologists to satisfy the needs of the Armed Services. He retained his chair at Chicago, where he became distinguished service professor, until 1950, but from 1947 onwards he spent about half his time in the University of Stockholm where he created yet another department of meteorology, this time of an avowedly international flavour. Stockholm was indeed his home from about 1949, but he ersntinued to make occasional extended visits to the United States, mainly for work at Woods Hole Oceanographic Institution.

Rossby's direct contributions to meteorology and oceanography wore rather closely phased to his various academic appointments. During the period when he was at the Massachusetts Institute of Technology, Rossby was largely concerned with the theory of atmospheric and oceanic turbulence and with meteorological thermodynamies. He developed the latter as a tool in air-mass analysis and sought the workings of large-scale atmospheric processes in isentropic analysis, that is, by the charting of the contours of isentropic surfaces. Others failed to advance the subject significantly by its aid, and the technique lapsed. But it led Rossby on to his major work, the form and behaviour of atmospheric flow on the planetary scale. Earlier work in this field had been almost entirely climatological, but Rossby dealt with the instantanoous pattern, a circumpolar system of 'long' waves most in evidence in the westerlies of the middle and upper troposphere, and its evolution. Well enough aware that all atmospheric motion is essentially thermally driven, Rossby sought to find how far a purely inertial model of the atmosphere would take him in the description of the large-scale flow field. This was characteristic of Rossby : not to attempt to solve the problem of atmospheric motion in all its bewildering complexity but to see whether major features could be accounted for in relatively simple terms. By about the end of his period at the Massachusetts Institute of Technology he had on the basis of the conservation of absolute vorticity developed the famous Rossby equation

$$
C=U-\beta\left(\frac{L}{2 \pi}\right)^{2}
$$

where $C$ is the speed of propagation of long waves of length $L$ in a zonal air current of speed $U$, and $\beta$ is the variation of the Coriolis parameter with latitude. For large wind speeds or low wave-lengths the waves are propagated downstream at relatively high speed, whereas for low wind speeds or large wave-lengths the waves may retrogress.

The Chicago period was one of elaboration and application of these ideas. Upper-air datas on pressure and wind fields were accumulating rapidly and the long-waves could be mapped with some thoroughness over a large part of the northern hemisphere on a dayto-day basis. The 'jet stream' was identified as the fast-moving core of air embedded in the upper longwaves and Rossby sought an explanation, not quite successful, in terms of conservation of vorticity and large-scale mixing.

I well remember a hot August day in Chicago in 1947 when I was privileged to attend the daily conference on the current large-scale synoptic situation at which the long-wave and jet ideas were under discussion and application. This was a period too when Rossby, with others, began to see the possibility of applying the hydrodynamical equations of his or other model atmospheres for numerical weather prediction, using the new high-speed, electronic computers. That research is still very active.

Dynamical problems were by no means dropped during the final Stockholm period, but Rossby was looking for new interests and found them in the study of atmospheric micro-chemistry. He organized a network of stations in Western Europe at which the concentration of various radicals, such as sulphate, chloride, etc., in the air and in precipitation, was measured on a routine basis to provide their distribution in space and time. Such information, Rossby believed, would lead to important advances in meteorology, oceanography and agricultural science. He leaves in Sweden workers who can be expected to continue this research from the point now reached.

An account of Rossby's interests and original work shows only a part of the great character he was. Probing, puckish, kindly, cultured, a great European and a great American, he was much honoured, both formally and by the many who could call him friend. A light has gone out and the world is in debt to Scandinavia for one of her great sons of geophysics. P. A. SHEPPARD 